J. Lake Sci.(湖泊科学), 2021, 33(2): 518-528

DOI 10. 18307/2021. 0216

(c) 2021 by Journal of Lake Sciences

\title{
长江下游沿江湿地升金湖越冬水鸟受食集团结构及生态位特征”
}

\author{
王新建 ${ }^{1,2}$, 周立志 ${ }^{1,2 * *}$, 陈锦云 ${ }^{3}$, 范少军 ${ }^{1,2}$ \\ ( 1 : 安徽大学资源与环境工程学院, 合肥 230601) \\ (2: 安徽大学湿地生态保护与修复安徽省重点实验室, 合肥 230601) \\ (3:淮南师范学院生物工程学院,淮南 232038)
}

\begin{abstract}
摘 要: 集团结构和生态位特征是量化动物群落组织过程的重要指标, 鸟类集团结构及其食物资源分割的分析对于理解 群落中不同鸟种生态适应性具有重要意义. 越冬水鸟集团结构和生态位特征取决于食物资源的丰富度和可获得性. 本文 通过对升金湖越冬水鸟的受食生境和受食行为的观察, 对水鸟群落的集团结构进行划分, 采用 Levins 指数和 Pianka 指数 计算生态位宽度和生态位重叠度. 结果表明,升金湖越冬水鸟可被划分为 4 个受食集团, 即 G1 浅水豚食集团、G2 草滩啄 食集团、G3 广食性集团和 G4 深水潜水受食集团. 在浅水和中水区的受食集团物种组成比深水区的水鸟集团丰富. G3 广 食性集团的生态位宽度远高于其余 3 个特化集团. 比较而言,所有水鸟物种的受食行为均较特化,但在䍃食生境方面却 较宽化. 同一集团内物种间的生态位重叠远高于集团间的生态位重叠. G3 广食性集团内物种的生态位重叠度低于其它 特化集团内物种的生态位重叠度. 研究结果表明, 升金湖越冬水鸟群落集团结构主要受食物资源空间配置及其可利用性 的影响. 水鸟群落结构和生态位特征的信息对监测升金湖湿地的质量和制定有效的湿地保护策略都具有重要意义.
\end{abstract}

关键词: 水鸟集团;受食行为;受食生境;生态位;升金湖

\section{Foraging guild structure and niche characteristics of wintering waterbirds at Lake Shengjin, lower reaches of the Yangtze River*}

\author{
Wang Xinjian ${ }^{1,2}$, Zhou Lizhi ${ }^{1,2 * *}$, Chen Jingyun ${ }^{3} \&$ Fan Shaojun ${ }^{1,2}$ \\ (1: School of Resources and Environmental Engineering, Anhui University, Hefei 230601, P.R.China) \\ (2: Anhui Province Key Laboratory of Wetland Ecosystem Protection and Restoration, Anhui University, Hefei 230601, P.R. \\ China) \\ (3: College of Biological Engineering, Huainan Normal University, Huainan 232038, P.R. China)
}

Abstract: Guild structure and niche characteristics are important indicators to quantify the assemble process of animal community. It is of great significance to analysis bird guild structure and food resource partitioning for understanding ecological adaptability of different bird species in a community. The guild structure and niche characteristics of wintering waterbirds depend on the abundance and availability of food resources. In this study we divided the guild structure of waterbird community based on the data of foraging habitat and foraging behavior of wintering waterbirds collected at Lake Shengjin, and calculated the niche width and niche overlap using Levin's index and Pianka index. The results showed that the waterbirds at Lake Shengjin can be divided into four different foraging guilds, namely the G1, pickers in shallow-water, G2, pickers in grassland, G3, generalists and G4, divers. The species composition of foraging guilds in shallow and middle-depth water is richer than that in deep water. The niche width of G3 generalists is much higher than that of the other three specialized species guilds. In comparison, the foraging behavior of all waterbird species is more specialized, but the foraging habitat is more generalized. The niche intra-guild overlap of waterbird species is much higher than that of inter-guilds. The niche overlap of species in G3 generalist is lower than that in other specialized guilds. The results show that the guild structure of wintering waterbird community at Lake Shengjin mainly affected by the spatial allocation and availability of food resources. The information of water bird community structure and niche characteristics is of great significance

* 2020-03-07 收稿;2020-08-07 收修改稿. 国家自然科学基金项目 (31472020)资助.

** 通信作者; E-mail: zhoulz@ ahu.edu.cn. 
for monitoring the quality of Lake Shengjin wetland and developing effective wetland protection strategies.

Keywords: Waterbird guild; foraging behavior; habitat use; niche overlap; Lake Shengjin

动物群落具有十分复杂的结构, 是物种间相互作用的结果 ${ }^{[1-2]}$. 集团 (Guild) 被认为是构建群落的基本 功能单元 ${ }^{[3-4]}$. 研究者普遍认为群落的结构和群落的组织过程, 就是相似的物种集团 (同资源种团) 通过竞争 资源, 形成资源利用格局的结果 ${ }^{[1,5-9]}$. 同属一个集团的物种彼此在资源利用上会有明显的重叠,所以同属一 个集团的物种间比属不同集团的物种间彼此更易产生竞争 ${ }^{[10]}$.

集团的结构和生态位特征可以用于量化动物群落组织过程 ${ }^{[2]}$. 集团划分的主要依据是资源位的利用情 况. 物种利用资源的宽度和重叠, 在群落结构的分析中非常重要, 前者表示物种生态特化的程度, 后者表示 种间潜在的相互作用水平. 目前, 研究群落的资源利用格局大部分是在生态位理论的框架下, 通过计算生态 位宽度 (niche breadth) 和生态位重叠度 (niche overlap) 两个指标来进行的 ${ }^{[1,-9,11]}$. Hutchinson 从空间和资源 利用等多方面考虑, 提出了多维生态位 (multidimensional niche) 概念 ${ }^{[12]}$. 基于这一定义, 生态位宽度就是指 物种对一定资源利用的程度. 生态位重叠度是指两个或者多个物种在利用同一资源上重叠的状况. 所以,生 态位宽度和生态位重叠为探讨群落的生态过程如对共享资源的竞争提供了一个间接的途径 ${ }^{[13]}$. 在研究资 源利用格局时,通常选择栖息地的利用空间、利用时间以及食性组成 3 个重要生态位维度,从而更好地理解 群落结构形成与群落组织的过程. 由于食性数据的缺乏,为了避免研究物种的食性,在假设物种使用不同的 受食行为能反映不同的食物类型 ${ }^{[14]}$ 的基础上, 大多数研究采用取食行为 (feeding behavior) 代替食物类型对 集团进行划分 ${ }^{[5,7-9,14-15]}$.

水鸟是湿地生态系统的重要指示类群, 其群落结构的维持和稳定取决于湿地环境质量. 食物资源丰富 度和可获得性是越冬水鸟生态的最重要的制约因素, 直接体现在群落各集团结构组成和生态位的变化. 近 几年随着长江中下游流域湖泊资源的过度利用,湿地严重退化,越冬水鸟的适宜栖息地不断丧失,在严酷寒 冷的越冬期食物、空间等资源极其有限,使越冬水鸟无论种间还是种內竞争更加激烈 ${ }^{[16-17]}$. 因此研究水鸟集 团结构和生态位对于水鸟越冬生态的理解和加强湿地管理具有重要意义. 升金湖是长江中下游的一个具有 代表性的浅水通江湖泊, 是越冬水鸟的重要聚集区. 近年来, 由于高强度养殖活动, 湖泊退化严重, 影响了水 鸟群落结构及其稳定性.

目前国内外对陆地和水鸟的集团结构和生态位研究均较多, 其中对水鸟的集团结构和生态位的研究多 集中在海滨湿地 ${ }^{[5,15]}$ 和湖泊湿地 ${ }^{[8-9]}$ 两种湿地类型的越冬水鸟群落上. Gatto 和 Liordos 分别对阿根廷巴塔哥 尼亚海岸的海滨湿地和希腊境内的地中海海滨湿地上的水鸟群落进行了集团结构和生态位的研究,认为海 滨湿地中各受食生境 (浅水到岸线潮汐带渐变的生境) 中水的含量是受食集团间资源分割最重要的划分因 素,集团间水鸟生态位重叠度较低,各集团间资源分割较为明显,集团内生态位重叠虽然较高,但水鸟集团 内通过利用不同的受食生境区域,产生了生态位分离, 从而达到共存 ${ }^{[5,18]}$. 例如 Liordos 研究表明, 浅水集团 内的水鸟物种通过利用不同深度的水域从而达到进一步的生态位分离 ${ }^{[18]}$. Pérez-Crespo 等于 2013 年研究墨 西哥一个陆缘湖泊湿地的水鸟群落,利用受食行为、栖息地利用和栖息地利用时间 3 个生态维度,对水鸟群 落进行集团划分, 通过对比基于零模型的集团结构, 探讨了水鸟群落集团结构的生态形成机制, 得出竞争因 素可能不是群落构建的唯一因素, 中性理论的随机因素也可能参与其中 ${ }^{[8]}$. Chatterjee 等于 2020 年对印度一 个湖泊湿地的越冬水鸟群落进行了研究, 水鸟群落的集团结构和生态位特征是两个重要的指标, 表征湿地 承载水鸟物种能力的指标 ${ }^{[9]}$. 国内越冬水鸟群落的研究很广泛, 特别是在长江中下游地区的湖泊湿地和人 海口的海滨湿地. 这些研究分析了群落的组成与多样性、栖息地的评价和利用、栖息地的演变对群落的影 响、空间分布、季节动态 ${ }^{[19-25]}$. 然而, 越冬水鸟群落的集团结构研究较少 ${ }^{[7]}$. 因此, 需要对水鸟群落结构进行 更多的研究.

本文旨在通过升金湖越冬水鸟的受食生境和受食行为的观察,对水鸟群落的集团结构进行划分, 分析 越冬水鸟各集团种间的生态位宽度和生态位重叠度特征, 探讨食物资源配置对越冬水鸟集团结构的影响, 为越冬水鸟及期栖息地管理提供科学依据. 


\section{1 研究方法}

\section{1 研究地点}

升金湖 ( $30^{\circ} 16^{\prime} \sim 30^{\circ} 26^{\prime} \mathrm{N}, 116^{\circ} 58^{\prime} \sim 117^{\circ} 11^{\prime} \mathrm{E}$ ) 位于安徽省长江南岸的池州市境内, 是长江中下游地区 典型的浅水通江湖泊之一, 分上湖、中湖和下湖三个部分. 水位在夏季 (6-8 月, 雨季) 上升到最高 $(17 \mathrm{~m})$, 湖泊面积达到最大 $\left(14000 \mathrm{hm}^{2}\right)$, 在冬季 (12月一次年 2 月, 早季) 水位下降到最低的 $10 \mathrm{~m}$, 湖泊面积达到最 小 $\left(3400 \mathrm{hm}^{2}\right)$. 湖泊所在地区属北亚热带湿润带, 年平均气温 $16.1^{\circ} \mathrm{C}, 1$ 月份平均气温 $4.0^{\circ} \mathrm{C}$. 年平均降雨量 为 $1600 \mathrm{~mm}$. 升金湖沉水植物优势种包括金鱼藻 (Ceratophyllum demersum) 、马来眼子菜 (Potamogeton malaia$n u s$ ) 和苦草 (Vallisneria spiralis); 漂浮植物优势种包括苂实 (Euryale ferox)、荢菜 (Nymphoides peltatum); 湖泊 岸边植物优势种包括曧草 (Phalaris arundinacea)、单性苔草 (Carex unisexualis)、灰化苔草 (Carex cinerascens)、朝天委陵菜 (Potentilla supine) 和酸模叶蓼 (Polygonum lapathifolium ${ }^{[26]}$. 湖泊周围农田主要种植 水稻、棉花和油菜. 冬季湖水退去, 泥滩暴露, 为越冬水鸟提供各种受食栖息地, 是东亚一澳大利西亚迁徙水 鸟重要的停歇和越冬地, 每年在此越冬的水鸟占整个长江中下游湿地水鸟总数的 $5 \% \sim 10 \%$, 越冬水鸟的种 类超过 60 种, 数量超过 5 万只, 其中数量较多的有豆雁 (Anser fabalis)、白额雁 (Anser albifrons)、白琵鹭 (Platalea leucorodia)、小天鹅 (Cygnus columbianus)、白头鹤 (Grus monacha) 等 ${ }^{[27]}$. 升金湖于 1986 年被批准为省级 自然保护区,于 1997 年成为国家级自然保护区, 2015 年列入国际重要湿地名录.

本研究区域位于升金湖上湖, 沿湖泊岸线设置调查样线, 在样线上设置观察点. 升金湖水鸟大多数分布 在上湖, 根据水鸟和受食生境的分布情况, 本研究共设置 7 个具有代表性的观察点 (图 1).

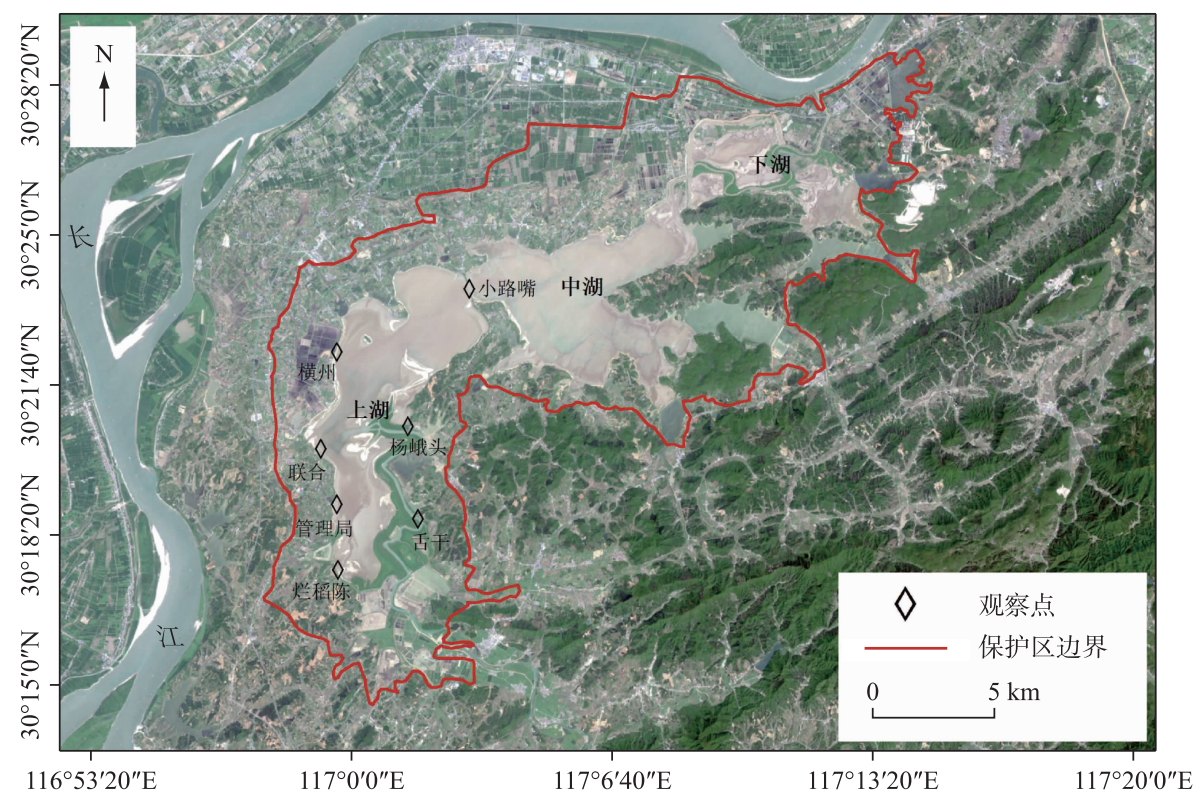

图 1 升金湖水鸟调查地点

Fig. 1 Study sites of waterbird survey at Lake Shengjin

\section{2 水鸟调查数据}

水鸟的调查时间为 2014 年 12 月至 2015 年 3 月, 每月进行 4 次,共 16 次, 调查时间为 7:00-11:00和 13:00-17:00. 每次调查从不同的位置和方向开始, 以避免顺序影响. 在观察点之间切换时, 将鸟群和个别 鸟类的移动情况考虑在内, 以避免重复收集同一个体的信息. 在每个观察点使用定点计数法, 观察半径为 $500 \mathrm{~m}$. 以双筒 $(8 \times 42)$ 和单筒 $(16 / 52 \times 80)$ 望远镜进行扫描取样法记录水鸟的受食行为和受食生境数据.

每次调查在 $2 \mathrm{~d}$ 内完成, 在每个观察点观察不少于 $2 \mathrm{~h}$, 各观察点计数时每 $30 \mathrm{~min}$ 扫描一次, 即每次调查 
对每个观察点的扫描次数不少于 4 次. 记录观察范围内各水鸟个体的受食行为和受食生境.

由于对同一个体的连续观测的样本并不是独立的, 会受时间自相关的影响 (每次观测通常与以前的观 测相关 ${ }^{[28]}$. 为了观测到每个物种尽可能多的代表性个体并避免对同一个体的连续观测, 调查采用初始观 察法 (即每次扫描时只记录各水鸟个体的第一次受食行为和受食生境), 扫描 4 次则记录 4 次. 这种方法根 据同一物种更多的个体抽样的初始观察, 确定该物种具有代表性的受食特征 ${ }^{[8-9,15]}$.

\section{3 受食行为的划分}

将受食行为方式定义如下: (D) 潜水取食, 整个身体潜人水面下取食; ( PM ) 用啉深人泥滩中两边挖掘 取食; (HS) 头部人水取食, 可以是运动也可以静止取食; (BS) 㗒部人水取食, 可以是运动也可以静止取食; (NS) 颈部人水取食, 可以是运动也可以静止取食; (FL) 在运动中喙部分人水滤取水中的食物; (PC) 在水 里、泥滩或草滩上的间歇的啄食的方式取食; (UP) 取食时倒立垂直人水, 身体不完全人水, 尾部和腿部在水 面以上 ${ }^{[29]}$.

\section{4 受食生境划分}

受食生境的划分参照 Pöysä 对生境的划分 ${ }^{[29]}$, 根据水深和植被两种因素划分的水鸟受食生境. 每个月 测量一次水深, 具体测量方法是在每个观察点位置从湖岸边朝湖中心每隔 $100 \mathrm{~m}$ 放置一根有浮标记号的铅 坠绳, 每个观察点放置 5 条记号绳. 此外每月还监测湖中心的深度, 以跟踪水位的变化.

划分了 9 种受食生境: (1) 水深大于 $30 \mathrm{~cm}$ 的开阔水域中心区, 有植被 (DWV) 或者无植被 (DW); (2) 水 深大于 $10 \mathrm{~cm}$ 小于 $30 \mathrm{~cm}$ 的开阔水域边缘区, 有植被 (MWV) 或者无植被 (MW); (3) 水深小于 $10 \mathrm{~cm}$ 的沿湖 岸线浅水区, 有植被 (SWV) 或 (SW) 无植被; (4) 紧邻浅水区的泥滩湿地, 有植被 (MUV) (即草滩) 或者无植 被 (MU) (即泥滩); (5) 紧邻湖边周围的水稻田 (RF).

\section{5 数据分析}

将观察到的取食记录建立数据矩阵, 舍弃记录次数少于 10 次的鸟种. 为了观测到每个物种尽可能多的 代表性个体并且避免对同一个体的连续观测, 我们只使用每个个体记录的第一次进食行为. 数据将分为 3 个矩阵:受食生境 ( 31 种 $\times 9$ 种生境变量)、受食行为 ( 31 种 $\times 8$ 种受食行为变量)、两种同时存在 ( 31 种 $\times 57$ 种受食行为与生境变量的组合). 矩阵的每一行代表一个不同的物种. 每一列代表一个不同的变量 (资源或 生态位). 每个记录表示取食个体的数量. 然后将矩阵项计算为物种对任何特定资源观察利用的比例. 这些 比例的计算方法是将所有资源的计数 (行) 相加, 然后将每个资源计数 (原始矩阵中的一个条目) 除以其总 数 (行总数). 因此对于每种鸟, 最终矩阵行中各项的和为 1.0. 这些一维 (受食生境和受食行为) 和二维矩阵 用于建立群落生态位宽度和生态位重叠.

\section{6 集团的划分}

采用聚类分析的方法划分集团. 为了减少变量分布的峰度, 我们将原始矩阵进行数据转换 (角变换 $y=$ $\left.\operatorname{arcsine} x^{0.5}\right)^{[8]}$. 将上述经过数据转换后的二维矩阵 (受食生境和受食行为组合的二维矩阵) 输人生态学软件 PC-ORD 5.0 进行聚类分析, 聚类方法采用欧式距离的离差平方和法.

\section{7 生态位的宽度和生态位重叠}

利用前面提到的单维和二维的原始矩阵 (受食生境 ( 31 种 $\times 9$ 种生境变量)、受食行为 ( 31 种 $\times 8$ 种受食 行为变量)、两种同时存在 ( 31 种 $\times 57$ 种受食行为与生境变量的组合) ) 来计算生态位宽度 (每个物种) 和生 态位重叠 (所有物种之间的重叠).

采取 Levins 指数和 Pianka 指数分别计算生态位宽度 ${ }^{\left[{ }^{[} 0\right]}$ 和生态位重叠指数 ${ }^{[31]}$. Levins 生态位宽度指数: $B=\left(1 / \Sigma P_{i}{ }^{2}\right), P_{i}$ 是物种 $i$ 利用每列资源的比例. 当每列至少有一个计数时 $B$ 最大; 当所有计数都在同列时 $B$ 最小. Pianka 指数: $O_{j k}=\left(\sum P_{i j} P_{i k}\right) /\left(\sum P_{i j}{ }^{2} \sum P_{i k}{ }^{2}\right)^{1 / 2}, P_{i j}$ 和 $P_{i k}$ 分别是物种 $j$ 和物种 $k$ 利用 $i$ 资源的相对比 例. Pianka 指数取值范围从 0 (两个物种之间没有共同使用的资源) 到 1 (资源使用完全重叠).

\section{2 结果}

\section{1 水鸟群落集团结构及其组成}

本研究共涉及 7 目 12 科 31 种水鸟, 其中 28 种冬候鸟和 3 种留鸟. 鹈形目有 1 科 1 种, 鹤䳽目有 1 科 2 
种,鸥形目有 1 科 2 种, 雁形目有 1 科 12 种,鹤形目有 2 科 2 种, 鹳形目有 3 科 5 种、鸭形目有 3 科 7 种. 雁

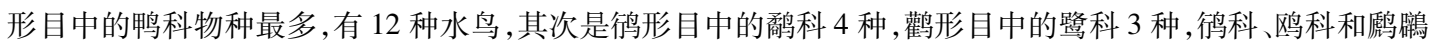
科各 2 种,其余 6 科,鸹鹚科、鹳科、噮科、鹤科、秧鸡科和反嘴璚科各有 1 种. 本研究对 31 种水鸟通过 1219 次扫描观察,一共观察了 50304 只受食个体 (附表 I). 划分了 9 种不同的受食栖息地和 8 种不同的受食行 为, 得出了 72 种这两个维度的组合, 但水鸟只使用了 57 种受食组合.

记录的鸟类中被列人《世界自然保护联盟濒危物种红色名录》( IUCN) 的有 4 种. 其中, 濒危 ( EN) 1 种: 东方白鹳 (Ciconia boyciana); 易危 (VU) 2 种: 鸿雁 (Anser cygnoides)、白头鹤; 近危 (NT) 1 种: 罗纹鸭 (Anas falcata). 列人 《中国重点保护名录》(PROT) 的鸟类有 5 种. 其中, I 级保护的有 2 种: 东方白鹳、白头鹤; II 级保护的有 3 种: 白琵路、小天鹅、白额雁.

根据受食行为和生境利用特征 (附表 II ), 通过聚类分析, 在欧氏距离 1.3 处, 可将水鸟群落结构划分为 4 个受食集团（图 2).（G1）浅水豚食集团（pickers in shallow-water）、(G2) 草滩啄食集团（pickers in grassland)、(G3) 泛化种集团 (generalists) 和 (G4) 深水潜水集团 (divers) 包含的物种数分别为 11 种、5 种、12 种和 3 种. 这 4 个受食集团分别主要利用 4 种不同水深类型的受食生境类型: 浅水泥滩区、草滩、中水区和深水 区. 利用浅水和中水的集团包含的物种数较多,而利用深水和草滩的集团包含的物种数较低.

第 1 集团 (G1) 浅水豚食集团, 主要是一些行璚类、鹭类和鹤鹳类, 这些涉禽主要在无植被的浅水区和泥 滩区受食,包括白腰草敄( Tringa ochropus)、青脚敄 ( T. nebularia)、鹤璚( T. erythropus)、反嘴璚 (Recurvirostra

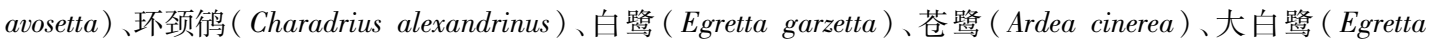
alba)、白额雁、东方白鹳、白头鹤. 该集团鸟类受食行为使用频率最高的是间歇型豚食行为方式 $(\mathrm{PC})$, 其次 是用鲒深人泥滩中两边挖掘取食的行为方式 (PM), 平均使用频率分别为 $86.5 \%$ 和 $9.9 \%$; 集团鸟类受食生境 使用频率最高的是浅水区 $(\mathrm{SW})$, 其次是泥滩 ( MU) , 平均使用频率分别为 $44.2 \%$ 和 $39.1 \%$. 所以, 该集团鸟 类是采用较为特化和单一的受食行为,并主要利用浅水和泥滩的受食生境的水鸟集团.

第 2 集团 (G2) 草滩啄食集团, 主要是一些在湿地草滩区受食的种类, 种类包括矶敄 (Tring a hypoleucos)、凤头麦鸡 (Vanellus vanellus)、黑水鸡 (Gallinula chloropus)、鸿㕍(Anser cygnoides) 和豆雁. 该集团 鸟类受食行为全部采用单一的间歇型豚食行为方式 $(\mathrm{PC})$, 使用频率为 $100.0 \%$; 集团鸟类受食生境使用频率 最高的是草滩 (MUV), 其次是泥滩 (MU), 平均使用频率分别为 $68.6 \%$ 和 $15.4 \%$. 所以, 该集团鸟类是采用单 一的豚食行为,并主要利用草滩的受食生境的水鸟集团.

第 3 集团 (G3)广食性集团, 主要是一些鸭类和鸥类, 在水域里通过喙、头、脖子和身体倒立垂直人水取 食的方式, 种类包括琵嘴鸭 (Anas clypeata)、赤颈鸭 (A. penelope)、罗纹鸭 (A. falcate)、斑嘴鸭 (A. poecilorhyn$c h a)$ 、针尾鸭 (A. acuta)、赤麻鸭 (Tadorna ferruginea)、绿翅鸭 (A. crecca)、绿头鸭 (A. platyrhynchos)、银鸥 (Larus argentatus)、红嘴鸥 (L. ridibundus)、小天鹅、白琵鹭. 该集团鸟类属于泛化种,使用各种受食行为,使 用频率较高的有颈部人水取食 (NS)、头部人水取食 (HS) 和身体倒立垂直人水取食 (UP) 3 种方式, 平均使 用频率分别为 $26.8 \% 、 25.3 \%$ 和 $21.1 \%$; 集团鸟类受食生境使用频率最高的是中水区 (MW), 其次是深水区 (DM), 平均使用频率分别为 $41.3 \%$ 和 $30.4 \%$. 所以, 该集团鸟类是采用各种受食行为, 并主要利用中水区和 深水区受食生境的水鸟集团.

第 4 集团 (G4) 深水潜水受食集团,主要是一些特化为深水区和中水区潜水取食的水鸟,包括普通扸鹚

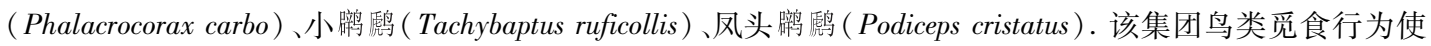
用频率最高的是潜水取食行为方式 (D), 平均使用频率为 $99.3 \%$; 集团鸟类受食生境使用频率最高的是深水 区 $(\mathrm{DW})$, 其次是中水区 $(\mathrm{MW})$, 平均使用频率分别为 $74.7 \%$ 和 $17.1 \%$. 所以, 该集团是采用较为特化和单一 的潜水受食行为,并主要利用深水区受食的水鸟集团.

\section{2 受食集团的生态位特征}

越冬水鸟群落所有物种的平均生态位宽度为 4.19 (两个维度)、2.14 (受食生境) 和 1.88 (受食行为) (表 3). 根据受食生境和受食行为二维矩阵计算的生态位宽度, 最宽的水鸟物种是赤麻鸭, 其次是绿头鸭, 最窄 的是黑水鸡, 其次是鸿雁. 根据受食生境计算的受食生态位宽度, 最宽的是白路和苍鹭, 其次是赤麻鸭和红 嘴鸥, 最窄的是黑水鸡, 其次是鸿雁. 根据受食行为计算的受食生态位宽度, 最宽的是绿头鸭, 其次是赤麻 


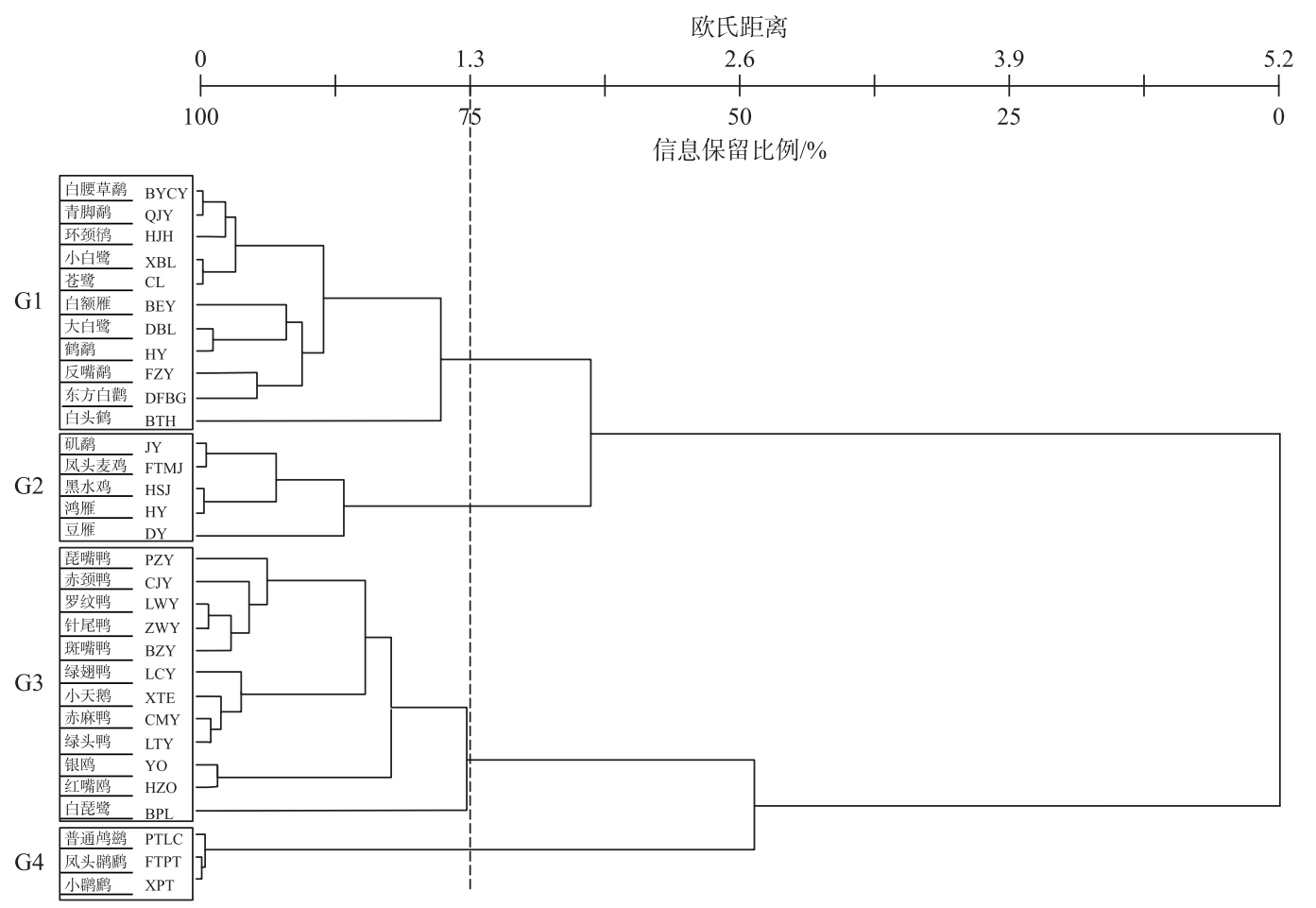

图 2 基于受食行为和受食生境两维生态位的水鸟集团聚类分析

(所有水鸟物种之间的平均欧氏距离用虚线表示(平均值为 1.3 ) (集团代码 (G1) 浅水啄食集团;

（G2）草滩啄食集团;（G3）广食性集团;（G4）深水潜水受食集团）

Fig. 2 Cluster analysis of waterbird guild based on the niche dimensions of feeding technique and feeding habitat

( The average Euclidean distance between all species pairs is indicated by a dashed line (mean value is 1.3 ).

Guild codes for the obtained guilds are (G1) pickers in shallow-water;

(G2) pickers in grassland; (G3) generalists; and (G4) divers)

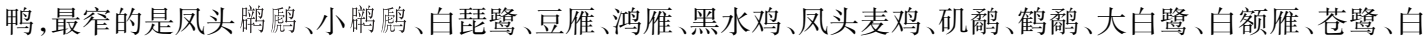

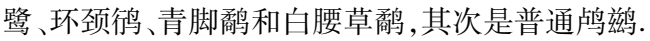

根据受食生境和受食行为二维矩阵计算的生态位宽度, G3 广食性集团的平均生态位宽度最宽,远高于 总体所有水鸟物种的平均生态位宽度和其它集团的平均生态位宽度; G2 草滩豚食集团平均生态位宽度最 窄.根据受食生境计算的生态位宽度, G1 浅水豚食集团平均生态位宽度最宽,其次是相差不大的 G3 广食性 集团; G2 草滩豚食集团平均生态位宽度最窄, 其次是相差不大的 G4 深水潜水受食集团. 根据受食行为计算 的生态宽度, G3 广食性集团平均生态位最宽,远高于其它 3 个集团和总体所有水鸟物种的平均生态位宽度; G1 浅水豚食集团、G2 草滩豚食集团和 G4 深水潜水受食集团的平均生态位宽度都非常窄,远低于 G3 广食 性集团平均生态位. 总之, G3 广食性集团的生态位宽度无论在哪个维度上都表现的较宽,在生境利用和受 食行为上都表现出很大的灵活性.

越冬水鸟群落所有物种之间的平均生态位重叠度为 0.35 (受食行为)、 0.41 (生境利用) 和 0.20 (两个维 度) (附表 III , IV). 相对于单维生态位重叠程度,二维生态位重叠程度较低,其中单维中的受食生境维度的生 态位重叠度较其它维度高. G1 集团中, 白路和苍路之间的生态位重叠最高, 白头鹤和鹤璚之间的生态位重 叠最低. G2 集团中, 鸿雁和黑水鸡之间的生态位重叠最高, 豆㷳和凤头麦鸡之间的生态位重叠最低. G3 集 团中, 罗纹鸭和斑嘴鸭之间的生态位重叠最高, 白琵路和红嘴鸥、银鸥、小天鹅之间的生态位重叠最低. G4

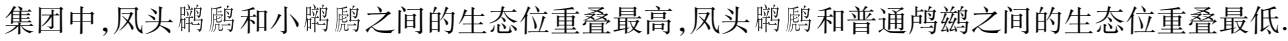


集团间生态位重叠低,集团内生态位重叠高. 同一集团内物种间的生态位重叠度平均值为 0.83 (受食行 为)、 0.78 (生境利用) 和 0.68 (两个维度), 远高于集团间的生态位重叠值 0.27 (受食行为)、 0.32 (生境利用) 和 0.07 (两个维度) (表 2). 根据受食生境和受食行为二维矩阵计算的生态位重叠度, G4 集团最高, 其次是 G1 集 团和 G2 集团. G3 集团的生态位重叠度 (0.49) 最低,低于其它特化集团内物种的生态位重叠度 ( $0.60 \sim 0.99)$.

升金湖越冬水鸟各集团种间的生态位有以下 4 个特征: 1) 升金湖越冬水鸟群落被划分的 4 个受食集 团, 其中 G3 集团的生态位宽度远高于其余 3 个特化集团;2) 升金湖越冬水鸟的受食行为较特化,在受食生 境方面却较宽化;3) 同一集团内物种间的生态位重叠远高于集团间的生态位重叠;4) 泛化集团内物种的生 态位重叠度低于其它特化集团内物种的生态位重叠度.

表 1 各集团水鸟的受食生态位宽度

Tab.1 The niche breadth of waterbirds foraging guild

\begin{tabular}{|c|c|c|c|c|c|c|}
\hline 集团 & 水鸟名称 & 学名 & 代码 & $\begin{array}{c}\text { 受食行为 } \\
(n=8)\end{array}$ & $\begin{array}{c}\text { 觅食生境 } \\
(n=9)\end{array}$ & $\begin{array}{c}\text { 受食行为和生境 } \\
(n=57)\end{array}$ \\
\hline \multirow[t]{12}{*}{ G1 } & 平均 & & & 1.16 & 2.33 & 2.76 \\
\hline & 白腰草璚 & Tringa ochropus & BYCY & 1.00 & 1.98 & 1.98 \\
\hline & 青脚鹬 & Tringa nebularia & QJY & 1.00 & 1.98 & 1.98 \\
\hline & 环颈微 & Charadrius alexandrinus & НJH & 1.00 & 1.59 & 1.59 \\
\hline & 白鹭 & Egretta garzetta & BL & 1.00 & 3.10 & 3.10 \\
\hline & 苍鹭 & Ardea cinerea & CL & 1.00 & 3.10 & 3.10 \\
\hline & 白额雁 & Anser albifrons & BEY & 1.00 & 2.85 & 2.85 \\
\hline & 大白路 & Egretta alba & DBL & 1.00 & 2.08 & 2.08 \\
\hline & 鹤璚 & Tringa erythropus & HY & 1.00 & 1.21 & 1.21 \\
\hline & 反嘴鹬 & Recurvirostra avosetta & FZY & 1.55 & 2.84 & 4.40 \\
\hline & 东方白鹳 & Ciconia boyciana & DFBG & 1.93 & 2.54 & 4.90 \\
\hline & 白头鹤 & Grusmonacha & BTH & 1.33 & 2.35 & 3.13 \\
\hline \multirow[t]{6}{*}{ G2 } & 平均 & & & 1.00 & 1.67 & 1.67 \\
\hline & 矶璚 & Tringa hypoleucos & JY & 1.00 & 1.60 & 1.60 \\
\hline & 凤头麦鸡 & Vanellus vanellus & FTMJ & 1.00 & 2.11 & 2.11 \\
\hline & 黑水鸡 & Gallinula chloropus & HSJ & 1.00 & 1.04 & 1.04 \\
\hline & 鸿雁 & Ansercygnoides & $\mathrm{HY}$ & 1.00 & 1.16 & 1.16 \\
\hline & 豆雁 & Anser fabalis & DY & 1.00 & 2.43 & 2.43 \\
\hline \multirow[t]{13}{*}{ G3 } & 平均 & & & 3.11 & 2.29 & 7.76 \\
\hline & 琵嘴鸭 & Anas clypeata & PZY & 3.98 & 2.28 & 9.07 \\
\hline & 赤颈鸭 & Anas penelope & CJY & 3.53 & 1.86 & 6.57 \\
\hline & 罗纹鸭 & Anas falcate & LWY & 3.42 & 2.16 & 7.39 \\
\hline & 斑嘴鸭 & Anas poecilorhyncha & $\mathrm{BZY}$ & 2.58 & 2.59 & 6.68 \\
\hline & 针尾鸭 & Anas acuta & ZWY & 3.65 & 2.28 & 8.32 \\
\hline & 赤麻鸭 & Tadorna ferruginea & CMY & 4.41 & 2.97 & 13.10 \\
\hline & 银鸥 & Larus argentatus & YO & 1.55 & 2.73 & 4.23 \\
\hline & 小天鹅 & Cygnus colunbianus & XTE & 3.11 & 2.21 & 6.87 \\
\hline & 红嘴鸥 & Larus ridibundus & $\mathrm{HZO}$ & 2.03 & 2.97 & 6.03 \\
\hline & 绿翅鸭 & Anas crecca & LCY & 3.61 & 2.00 & 7.22 \\
\hline & 绿头鸭 & Anas platyrhynchos & LTY & 4.42 & 2.06 & 9.11 \\
\hline & 白琵鹭 & Platalea leucorodia & BPL & 1.00 & 1.36 & 1.36 \\
\hline \multirow[t]{5}{*}{ G4 } & 平均 & & & 1.02 & 1.69 & 1.72 \\
\hline & 普通鸹鹚 & Phalacrocorax carbo & PTLC & 1.05 & 1.81 & 1.90 \\
\hline & 凤头鸬鸪 & Podiceps cristatus & FTPP & 1.00 & 1.53 & 1.53 \\
\hline & 小鹈鹤 & Tachybaptus ruficollis & XPT & 1.00 & 1.72 & 1.72 \\
\hline & 总平均 & & & 1.88 & 2.14 & 4.19 \\
\hline
\end{tabular}


表 2 各集团内、集团间生态位重叠值

Tab.2 Mean overlap values of inter-guild and intra-guild niche

\begin{tabular}{ccccc}
\hline \multirow{2}{*}{} & & \multicolumn{3}{c}{ 生态位重叠值 } \\
\cline { 3 - 5 } & & 受食行为 & 生境利用 & 䍃食行为和生境利用 \\
\cline { 3 - 5 } 集团内 & G1 平均值 & 0.82 & 0.77 & 0.65 \\
& G2 平均值 & 1.00 & 0.60 & 0.60 \\
& G3 平均值 & 0.61 & 0.75 & 0.48 \\
& G4 平均值 & 1.00 & 0.99 & 0.99 \\
& 总平均值 & 0.83 & 0.78 & 0.68 \\
集团间 & G1 与 $G 2$ & 1.00 & 0.17 & 0.17 \\
& G1 与 G3 & 0.11 & 0.48 & 0.05 \\
& G1 与 G4 & 0.00 & 0.09 & 0.00 \\
& G2 与 G3 & 0.48 & 0.36 & 0.17 \\
& G2 与 G4 & 0.00 & 0.20 & 0.00 \\
& G3 与 G4 & 0.03 & 0.61 & 0.02 \\
& 总平均值 & 0.27 & 0.32 & 0.07 \\
\hline
\end{tabular}

\section{3 讨论}

\section{1 食物资源对水鸟群落集团结构的影响}

本研究通过 2 个受食生态维度- 1 个水平(受食生境)生态维度和 1 个垂直(受食行为)生态维度,描 述和分析了升金湖越冬水鸟群落的集团结构和资源利用格局. 鸟类群落集团结构和生态位特征的研究不仅 有助于我们构建一个评估生态系统产品和服务的生态指标, 而且有助于从另一个角度来检测和评估不断变 化的环境条件 ${ }^{[32-33]}$. 水鸟是湿地生态系统的重要指示类群, 其群落结构的维持和稳定直接反映了湿地环境 的质量. 所以研究湿地水鸟的群落集团结构和生态位特征对于湿地的管理和质量评估具有十分重要的意义.

食物资源在不同水深区域的空间配置直接决定水鸟群落受食集团的划分. 湿地适宜的理化条件促进了 多种植被和相关生物群落的发生和发展 ${ }^{[32-33]}$, 能为越冬受食的水鸟提供各种水深的受食生境. 水深是水鸟 群落受食集团间资源分割最重要的划分因素 ${ }^{[34-37]}$. 水深除限制水鸟进人受食栖息地外, 还会影响水鸟的净 能量摄取量, 水深越大受食效率越低. 与在较浅的水深处获得更高的净能量相比, 水鸟在水深较深处获得较 少的净能量, 这鼓励更多的水鸟在浅水处受食 ${ }^{[38-39]}$. 大量研究表明浅水有更多的有机物和水下植物床, 能提 供更丰富的食物资源 ${ }^{[39-40]}$. 所以浅水比深水能容纳更多的物种. 有些研究表明决定水鸟群落受食集团划分 的主要因素就是食物资源的区域空间配置 ${ }^{[5,15,41]}$. 本研究也得出类似的结果: 升金湖越冬水鸟被划分的 4 个 受食集团, 基本按照不同水深进行受食生境的资源分割, 划分为草滩区、浅水泥滩区、中水区和深水区. 其 中, 主要利用浅水区受食生境的水鸟集团 G1 具有较为丰富的物种多样性(11 种). 本研究还发现不仅浅水 区受食的水鸟集团具有较高的多样性, 中水区受食的水鸟集团 (12 种) 也具有丰富的物种多样性. 这可能是 升金湖食物资源丰富度或者可获得性降低, 导致越冬水鸟能利用浅水的两个集团 (G1 和 G3) 间竞争释放的 结果. G3 集团大部分是鸭类, 偏好水下植被丰富的湿地受食, 能采用喙人水、头人水、颈人水和倒立身体人 水等受食行为在不同水深处受食. 随着越冬季食物资源丰富度和可获得性的降低, 受食效率较高的浅水区 竞争日趋激烈, 导致泛化种集团 G3 的水鸟物种被迫选择受食效率其次的中水区.

食物资源的波动会影响群落的受食集团构成, 特别是特化集团的组成. 生态位宽度较宽的集团物种能 利用多种受食行为和受食生境, 被认为是泛化种 (generalists). 而生态位宽度较窄的集团物种, 仅能利用单 一的受食行为和受食生境的集团物种是特化种 (specialists) ${ }^{[39]}$. 当食物资源 (受食生境)波动时,对于生态位 较宽的泛化种集团而言影响较小, 但对于特化种集团影响较大. 本研究中, 升金湖越冬水鸟可分为 3 个特化 种集团, 1 个广食性集团. 如特化集团 G1 主要是是一些衍敄类、鹭类和鹤鹳类等涉禽. 这些涉禽利用啄食行 为适时地开发具有特定特征地区中的食物资源, 如泥滩区和浅水区 ${ }^{[40]}$, 这些物种的存在和丰富度是受限于 
湖泊水位的有规律的波动 ${ }^{[8]}$. 相比之下泛化种集团在受食行为和受食生境两个维度上都有更宽的生态位宽 度, 受影响较小. 如 $\mathrm{G} 3$ 集团主要是鸭类和鸥类等游禽, 其利用㗒、头、颈、身体倒置等部位深人水面, 在湖泊 的深水区、中水区和浅水区等不同深度的多个受食生境受食, 可有效减缓食物资源的波动带来的影响.

\section{2 食物资源对水鸟群落的生态位特征的影响}

食物资源的波动会影响特化集团物种的受食生态位宽度. 受食生态位有受食行为和受食生境两个重要 的维度, 是影响水鸟群落集团结构及其资源分割的主要影响因素 $7-8,11,18,41-42]$. 食物资源受限时, 水鸟可能选 择两种受食策略一调整受食行为和选择新的受食生境. 大多研究表明,特化集团的水鸟多采取选择新的受食 生境这一受食策略, 从而在生态位宽度上表现出水鸟受食行为较特化, 而受食生境却较宽化的生态位特 征 ${ }^{[8,42]}$. 本研究中, 升金湖在冬季初期由于黄湓闸的放水捕鱼, 湖泊水位降低, 暴露了湖滩湿地, 食物资源可 获得性极高, 冬季后期由于湖滩暴露时间过长干旱板结, 造成湖底沉水植物退化, 草滩土地硬度增大, 使水 鸟的食物资源减少且获得性变差. 由于升金湖在整个冬季食物资源空间配置的波动变化, 导致了水鸟物种 采取选择开发新的受食生境的受食策略,在生态位上表现为受食生境的生态位宽度大于受食行为的生态位 宽度. 如 G1 集团选取更多的受食生境, 从而导致该集团中水鸟的受食生境生态位宽度最大. G1 集团主要利 用的生境除了主要的浅水区和泥滩外, 还有水稻田、草滩和中水区等. 在冬季后期在食物资源有限的情况 下,竞争的压力变大,该集团很多水鸟都比以往增加了水稻田的受食生境利用率, 如白头鹤 ${ }^{[42-43]}$.

食物资源在不同水深的区域空间配置及其波动影响群落集团间和集团内物种生态位的重叠. 食物资源 在不同水深的区域空间配置, 降低了集团间物种受食生态位的重叠, 食物资源的波动增加了集团内物种受 食生态位的重叠. 所以群落集团表现出同一集团内物种间的生态位重叠远高于集团间物种之间的生态位重 叠的特征. 生态位重叠回答了水鸟物种如何对群落资源进行空间划分的问题. 集团间生态位重叠取决于各 集团间在受食行为和受食生境两个维度上的重叠度. 水深因素将食物资源划分为不同空间区域,将受食生 境分割开, 在受食生境利用上降低集团间相互竞争. 各集团内的水鸟物种在各自的空间区域内利用不同的 受食行为共同利用生境资源. 食物资源波动时, 集团内的水鸟物种会产生激烈的竞争, 生态位重叠度较高. 很多类似的研究表明在同一个集团内的物种之间存在强烈的竞争 ${ }^{[8,39,41]}$, 这样的集团通常为物种数中等或 者小的集团 ${ }^{[9,18]}$. 除去生境资源过剩的情况,一般认为群落的集团结构是通过激烈的种间竞争产生的 ${ }^{[33]}$. 本 研究也得出类似的结果, 同一集团内物种间的生态位重叠远高于集团间物种间的生态位重叠. 另外,特化种 集团内的水鸟物种生态位重叠度 $(0.60 \sim 0.99)$ 高于泛化种集团内水鸟物种的生态位重叠度 $(0.48)$. 由于泛 化种具有较宽的生态位宽度,同样的资源压力下, 比起特化集团泛化集团内部竞争程度更低.

本研究结果还表明: 越冬水鸟中的受胁物种和最大数量的物种主要在 G1 集团和 G2 集团中. G1 浅水豚 食集团中,集团鸟类受食生境使用频率最高的是浅水区和泥滩; G2 草滩豚食集团中,集团鸟类受食生境使 用频率最高的是草滩和泥滩. 所以,浅水、泥滩和草滩生境对于保护物种具有十分重要的意义.

\section{4 结论}

从升金湖越冬水鸟受食集团的结构和生态位特征可以反映出升金湖水鸟群落集团结构的划分主要受 食物资源空间配置及其可利用性的影响, 水深是最重要的资源分割因素. 升金湖水鸟群落在湖泊湿地生境 退化的情况下, 食物资源的波动对特化种集团影响较大, 对泛化种集团影响较小. 所以维持越冬水鸟群落集 团结构稳定的关键是维持特化种集团的受食生境要求. 浅水湿地生境是升金湖的越冬水鸟群落特化集团主 要利用的受食生境. 因此保护浅水湿地生境是保持升金湖越冬水鸟群落稳定的关键.

\section{5 附录}

附表 I IV 见电子版( DOI: 10.18307/2021.0216).

\section{6 参考文献}

[ 1 ] Winemiller KO, Pianka ER. Organization in natural assemblages of desert lizards and tropical fishes. Ecological Monographs, 1990, 60(1): 27-55. DOI: 10.2307/1943025. 
[ 2 ] Palmer TM, Stanton ML, Young TP. Competition and coexistence: Exploring mechanisms that restrict and maintain diversity within mutualist guilds. The American Naturalist, 2003, 162(S4) : 63-79. DOI: 10.1086/378682.

[ 3 ] Simberloff D, Dayan T. The guild concept and the structure of ecological communities. Annual Review of Ecology and Systematics, 1991, 22(1): 115-143.

[ 4 ] Hawkins CP, MacMahon JA. Guilds: the multiple meanings of a concept. Annual Review of Entomology, 1989, 34(1): 423-451. DOI: 10.1146/annurev.en.34.010189.002231.

[ 5 ] Gatto A, Quintana F, Yorio P. Feeding behavior and habitat use in a waterbird assemblage at a marine wetland in coastal Patagonia, Argentina. Waterbirds, 2008, 31(3) : 463-471. DOI: 10.1675/1524-4695-31.3.463.

[ 6 ] Liu B, Zhou LZ, Wang WG et al. Seasonal dynamics of the avian guild structure of mountain secondary forest in Dabieshan mountain. Zoological Research, 2009, 30(3) : 277-287. [刘彬, 周立志, 汪文革等. 大别山山地次生林鸟类群落集团 结构的季节变化. 动物学研究, 2009, 30(3): 277-287.]

[ 7 ] Chen JY, Zhou LZ. Guild structure of wintering waterbird assemblages in shallow lakes along Yangtze River in Anhui Province, China. Acta Ecologica Sinica, 2011, 31(18): 5323-5331. [陈锦云, 周立志. 安徽沿江浅水湖泊越冬水鸟群落 的集团结构. 生态学报, 2011, 31(18): 5323-5331.]

[ 8 ] Pérez-Crespo M, Fonseca J, Pineda-López R et al. Foraging guild structure and niche characteristics of waterbirds in an epicontinental lake in Mexico. Zoological Studies, 2013, 52(1) : 54. DOI: 10.1186/1810-522x-52-54.

[ 9 ] Chatterjee A, Adhikari S, Pal S et al. Foraging guild structure and niche characteristics of waterbirds wintering in selected sub-Himalayan wetlands of India. Ecological Indicators, 2020, 108: 105693. DOI: 10.1016/j.ecolind.2019.105693.

[10] Yang G, Xu J, Wang Y et al. The influence of vegetation structure on bird guilds in an urban park. Acta Ecologica Sinica, 2015, 35(14) : 4824-4835. [杨刚, 许洁, 王勇等. 城市公园植被特征对陆生鸟类集团的影响. 生态学报, 2015, 35 (14) : 4824-4835.]

[11] Pöysä H, Poysa H. Resource utilization pattern and guild structure in a waterfowl community. Oikos, 1983, 40(2) : 295. DOI: $10.2307 / 3544594$.

[12] Hutchinson GE. Homage to santa Rosalia or why are there so many kinds of animals? The American Naturalist, 1959, 93 (870) : 145-159. DOI: $10.1086 / 282070$.

[13] MacNally RC. On assessing the significance of interspecific competition to guild structure. Ecology, 1983, 64(6): 16461652. DOI: $10.2307 / 1937517$.

[14] Wiens JA. The ecology of bird communities. Cambridge: Cambridge University Press, 1992.

[15] Green AJ. Comparative feeding behaviour and niche organization in a Mediterranean duck community. Canadian Journal of Zoology, 1998, 76(3) : 500-507. DOI: 10.1139/z97-221.

[16] Jiang HX, Xu WB, Qian FW et al. Impact of habitat evolvement and human disturbance on wintering water birds in Shengjin Lake of Anhui Province, China. Chinese Journal of Applied Ecology, 2007, 18(8) : 1832-1836. [江红星, 徐文 涁, 钱法文等. 栖息地演变与人为干扰对升金湖越冬水鸟的影响. 应用生态学报, 2007, 18(8): 1832-1836.]

[17] Wang Y, Fan BL, Ding YR et al. The current situation and discussion on wetland ecological restoration of the middle and lower Yangtze River. China Water Resources, 2011, (13) : 4-6. [王越, 范北林, 丁艳荣等. 长江中下游湿地生态修复 现状与探讨. 中国水利, 2011, (13): 4-6. ]

[18] Liordos V. Foraging guilds of waterbirds wintering in a Mediterranean coastal wetland. Zoological Studies, 2010, 49(3): 311-323.

[19] He WY, Shao MQ, Zhi YJ et al. Waterbird diversity in three reclamation regions of Poyang Lake. Chinese Journal of Ecolo$g y, 2019,38(9): 2765-2771$. [何文韵, 邵明勤, 植毅进等. 鄱阳湖三个垦殖场的水鸟多样性. 生态学杂志, 2019, 38(9) : 2765-2771.]

[20] Yang L, Dong B, Wang Q et al. Habitat suitability change of water birds in Shengjinhu national nature reserve, Anhui Province. J Lake Sci, 2015, 27(6) : 1027-1034. DOI: 10.18307/2015.0606. [杨李, 董斌, 汪庆等. 安徽升金湖国家 级自然保护区水鸟生境适宜性变化. 湖泊科学, 2015, 27(6) : 1027-1034.]

[21] Xia SX, Liu GH, Yu XB et al. Importance assessment of wintering habitats for migratory waterfowl in Lake Poyang. J Lake Sci, 2015, 27(4) : 719-726. DOI: 10.18307/2015.0421. [夏少霞, 刘观华, 于秀波等. 鄱阳湖越冬水鸟栖息地评 价. 湖泊科学, 2015, 27(4): 719-726.]

[22] Fan XZ, Zhang LQ, Yuan L et al. An analysis on spatio-temporal dynamics of suitable habitats for waterbirds based on spatial zonation at Chongming Dongtan, Shanghai. Acta Ecologica Sinica, 2011, 31(13): 3820-3829. [范学忠, 张利 权，袁琳等. 基于空间分带的崇明东滩水鸟适宜生境的时空动态分析. 生态学报, 2011, 31(13) : 3820-3829.]

[23] Zhang B, Yuan X, Pei EL et al. Change of waterbird community structure after the intertidal mudflat reclamation in the 
Yangtze River Mouth: A case study of NanHui Dongtan area. Acta Ecologica Sinica, 2011, 31(16) : 4599-4608. [张斌, 袁晓, 裴恩乐等. 长江口滩涂围垦后水鸟群落结构的变化一一以南汇东滩为例. 生态学报, 2011, 31 (16): 4599-4608. ]

[24] Yang XT, Niu JY, Luo ZK et al. The impact of natural succession process on waterbird community in a abandoned fishpond at Chongming Dongtan, China. Acta Ecologica Sinica, 2013, 33(13): 4050-4058. [杨晓婷, 牛俊英, 罗祖奎等. 崇明东滩抛荒鱼塘的自然演替过程对水鸟群落的影响. 生态学报, 2013, 33(13): 4050-4058.]

[25] Zhang N, Li YK, Shan J et al. Community structure, abundance and spatial distribution of water birds wintering in Poyang Lake wetland. J Lake Sci, 2019, 31(1) : 183-194. DOI: 10.18307/2019.0117. [张娜, 李言阔, 单继红等. 鄱阳湖枯 水期延长背景下越冬水鸟群落结构、丰富度及其空间分布格局. 湖泊科学, 2019, 31(1) : 183-194.]

[26] Xu LL, Xu WB, Sun QY et al. Flora and vegetation in Shengjin Lake. Journal of Wuhan Botanical Research, 26(3) : 264270. [许李林, 徐文涁, 孙庆业等. 升金湖植物区系及其群落演变. 武汉植物学研究, 2008, 26(3) : 264-270.]

[27] Barter M, Lei G, Cao L eds. Waterbird survey of the middle and lower Yangtze River Floodplain (February 2005). Beijing: China Forestry Publishing House, 2006. [马克 - 巴特 (Mark Barter), 雷刚, 曹垒等. 长江中下游水鸟调查报告 (2005 年 2 月). 北京: 中国林业出版社, 2006.]

[28] Hejl SJ, Verner J, Bell GW. Sequential versus initial observations in studies of avian foraging. Studies in Avian Biology, $1990,13(13)$ : 166-173.

[29] Pöysä H. Temporal and spatial dynamics of waterfowl populations in a wetland area-A community ecological approach. Ornis Fennica, 1984, 61(4) : 99-108.

[30] Levins R. Evolution in changing environments: Some theoretical explorations. Princeton: Princeton University Press, 1968.

[31] Pianka ER. The structure of lizard communities. Annual Review of Ecology and Systematics, 1973, 4(1) : 53-74.

[32] Cintra R. Waterbird community composition in relation to lake physical traits and wetland limnological conditions in the Amazon basin. Hydrobiologia, 2019, 826( 1) : 43-65. DOI: 10.1007/s10750-018-3676-y.

[33] Chatterjee A, Adhikari S, Mukhopadhyay SK. Effects of waterbird colonization on limnochemical features of a natural wetland on buxa tiger reserve, India, during wintering period. Wetlands, 2017, 37(1) : 177-190.

[34] Jin X, Ren XT, Peng HB et al. Habitat use and factors affecting distribution of wintering waterbirds in the wetland restoration area at Chongming Dongtan. Chinese Journal of Zoology, 2013, 48(5) : 686-692. [ 金欣, 任晓形, 彭鹤博等. 崇明 东滩鸟类栖息地优化区越冬水鸟的栖息地利用及影响因子. 动物学杂志, 2013, 48(5) : 686-692.]

[35] Zhang Y, Xie HB, Zeng WB et al. Analysis on the waterbird community structure and its habitat on the artificial wetlands in spring in Chongming Dongtan, China. Chinese Journal of Zoology, 2014, 49(4): 490-504. [张姚, 谢汉宾, 曾伟斌 等. 崇明东滩人工湿地春季水鸟群落结构及其生境分析. 动物学杂志, 2014, 49(4) : 490-504.]

[36] Zhang SX, Wang RX, Shen JX et al. Potential relationship of wintering waterbirds community composition and water-level fluctuation in lake Erhai. Asian Journal of Ecotoxicology, 2018, 13(4): 143-148. [张淑霞, 王荣兴, 沈建新等. 洱海冬 季水鸟群落结构与水位变化的潜在关系. 生态毒理学报, 2018, 13(4) : 143-148.]

[37] Wang XY, Jiang B, Tian ZF et al. Impact of water level changes in Lake Caizi (Anhui Province) on main wetland types and wintering bird habitat during wintering period. J Lake Sci, 2018, 30(6) : 1636-1645. DOI: 10.18307/2018.0615. [王晓媛, 江波, 田志福等. 冬季安徽菜子湖水位变化对主要湿地类型及冬候鸟生境的影响. 湖泊科学, 2018,30 (6) : 1636-1645.]

[38 ] Kushlan JA. Sympatric foraging of little egrets and snowy egrets in Barbados, west Indies. Waterbirds, 2007, 30 (4) : 609-612.

[39] Elafri A, Belhamra M, Houhamdi M. Comparing habitat preferences of a set of waterbird species wintering in coastal wetlands of North Africa: Implication for management. Ekológia (Bratislava), 2017, 36(2) : 158-171. DOI: 10.1515/eko2017-0014.

[40] Skagen SK, Knopf FL. Migrating shorebirds and habitat dynamics at a prairie wetland complex. The Wilson Bulletin, 1994, 106( 1$)$ : 91-105.

[41] Jaksic FM, Medel RG. Objective recognition of guilds: Testing for statistically significant species clusters. Oecologia, 1990, 82(1) : 87-92. DOI: 10.1007/bf00318537.

[42] Zhou B, Zhou LZ, Chen JY et al. Diurnal time-activity budgets of wintering hooded cranes (Grus monacha) in Shengjin lake, China. Waterbirds, 2010, 33(1) : 110-115. DOI: 10.1675/063.033.0114.

[43] Zhao FJ, Zhou LZ, Xu WB. Habitat utilization and resource partitioning of wintering hooded cranes and three goose species at Shengjin Lake. Chinese Birds, 2013, 4(4) : 281-290. 


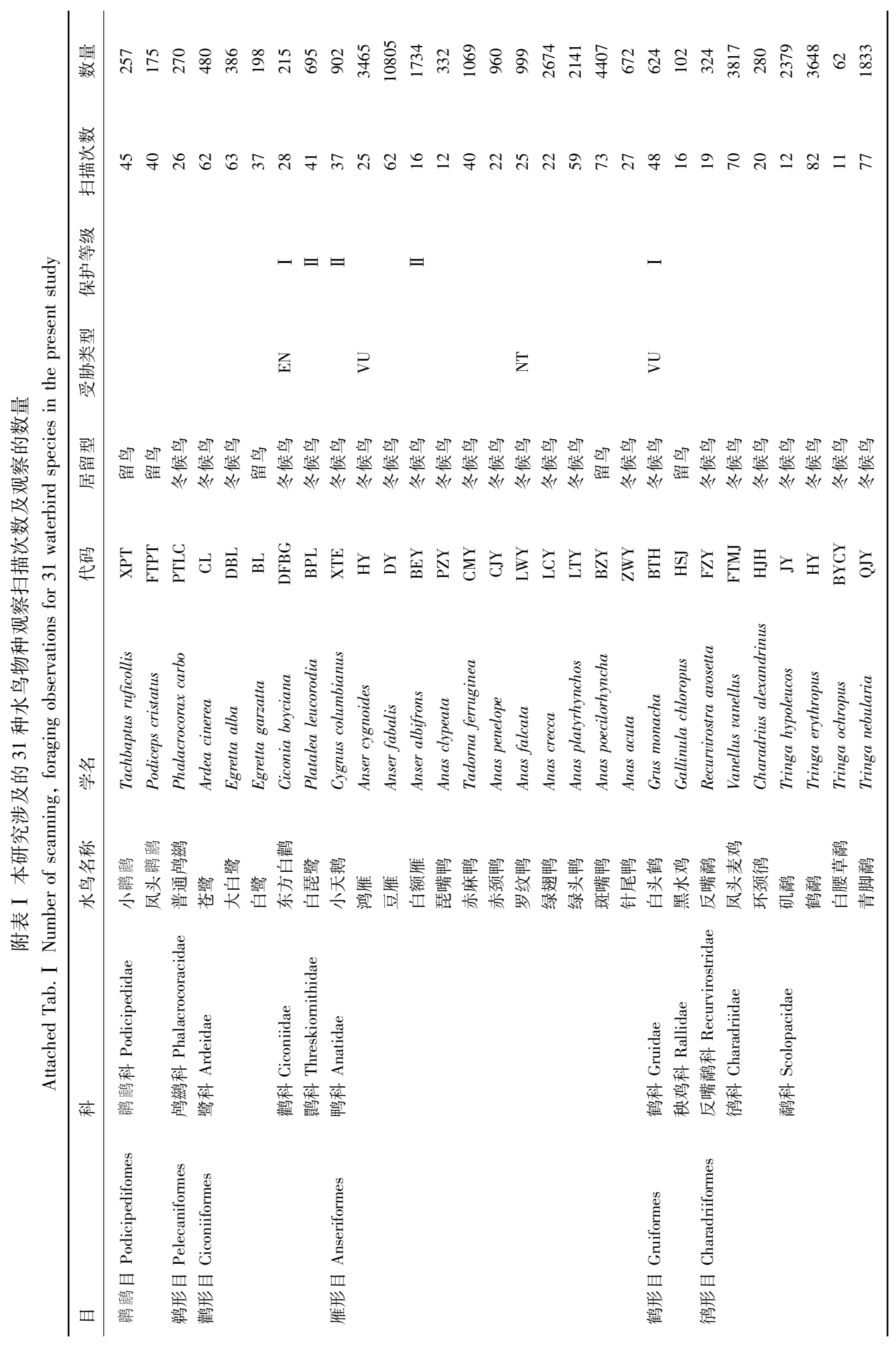




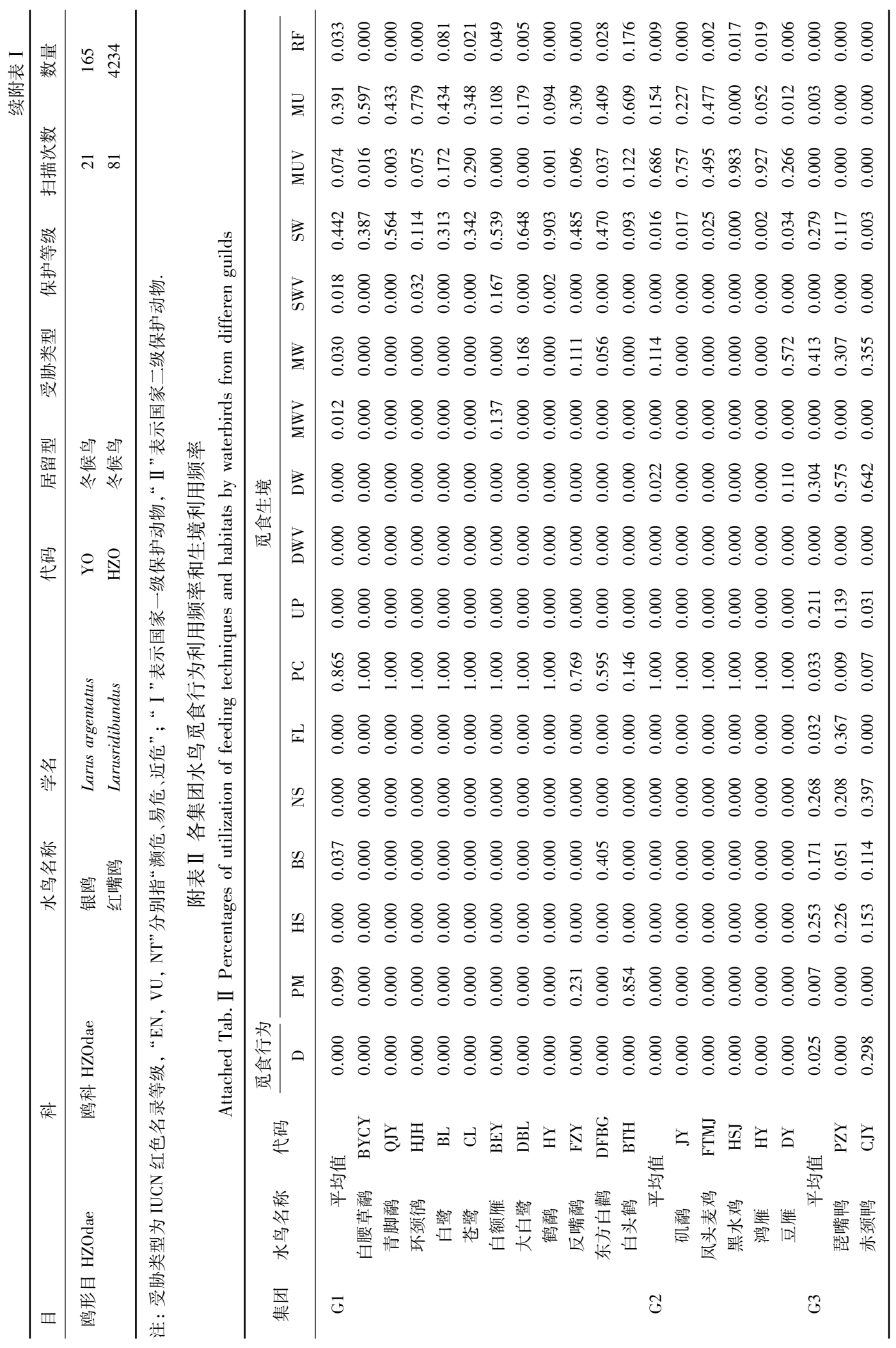



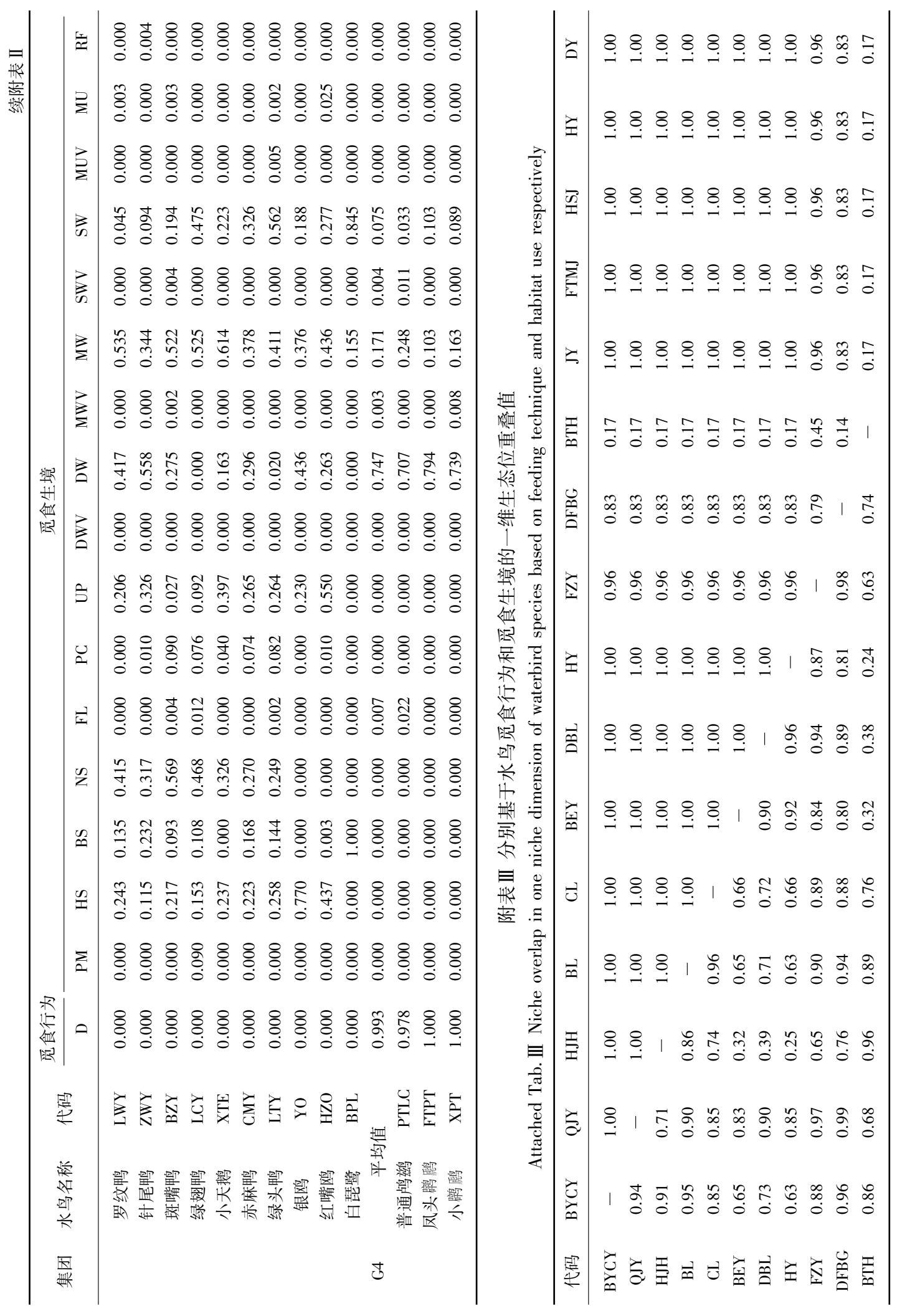


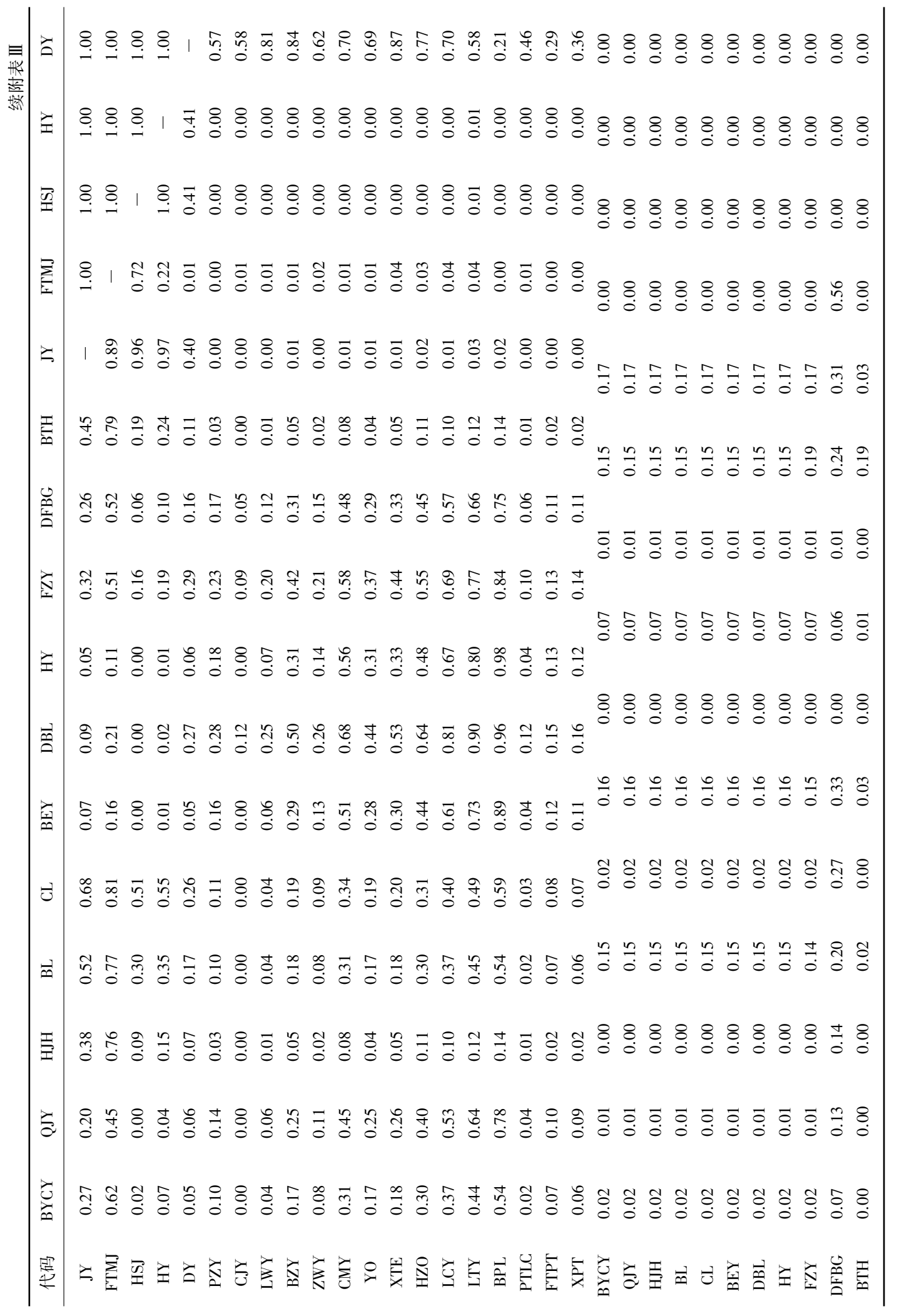




\begin{tabular}{|c|c|c|c|}
\hline 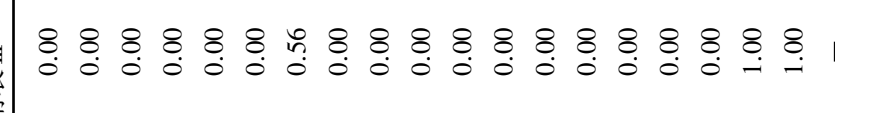 & & $\Xi$ & \\
\hline 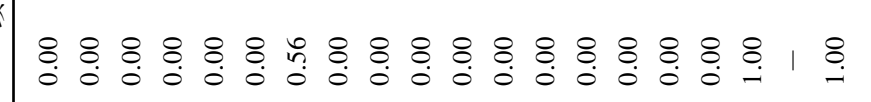 & & $\nexists$ & \\
\hline 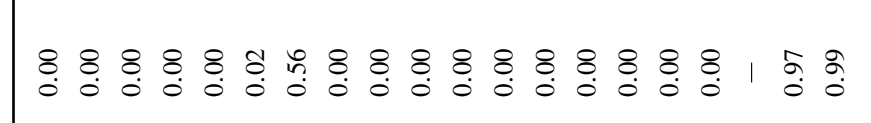 & 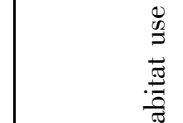 & $\stackrel{9}{2}$ & \\
\hline 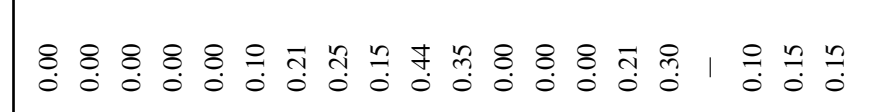 & & 产 & \\
\hline 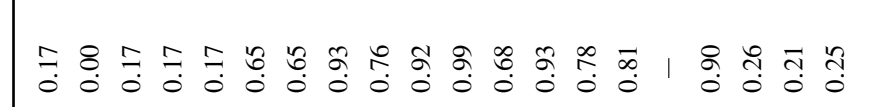 & & $\succeq$ & \\
\hline 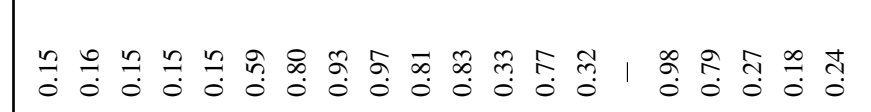 & 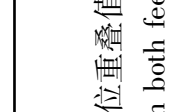 & 垔 & \\
\hline $\bar{\vdots}$ & 基怘 & 啚 & \\
\hline 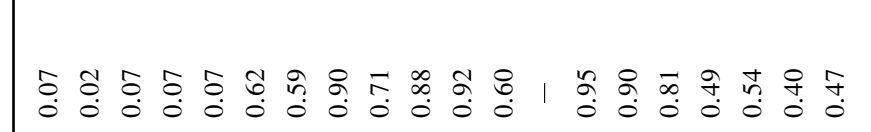 & 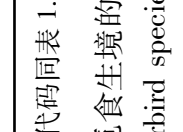 & 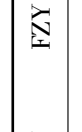 & \\
\hline 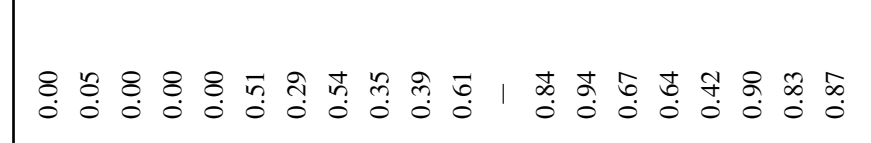 & 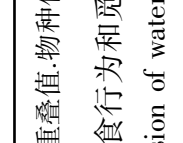 & $\mid \vec{x}$ & \\
\hline 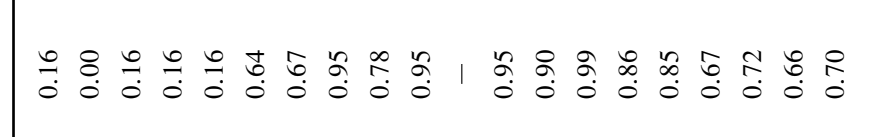 & 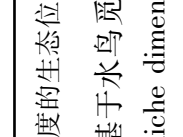 & 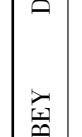 & \\
\hline 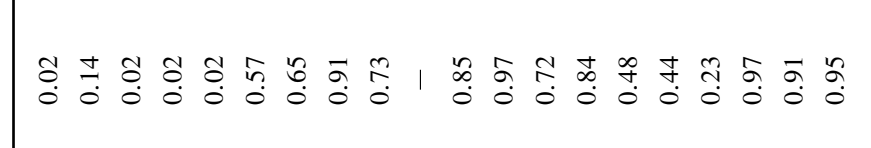 & 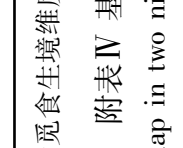 & 3 & \\
\hline 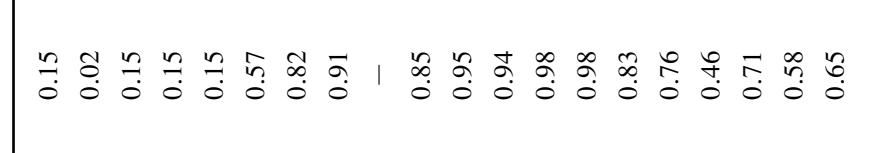 & 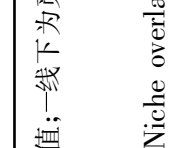 & $\vec{\mu}$ & $1:$ \\
\hline 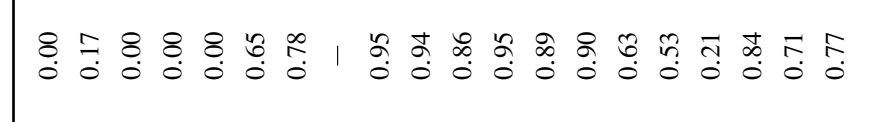 & 量 & 言 & 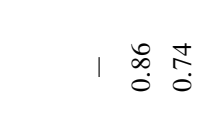 \\
\hline 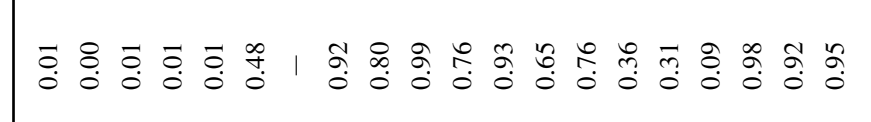 & 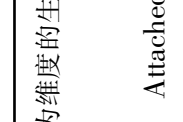 & $\succsim$ & $\mid \begin{aligned} 5 \\
0\end{aligned}$ \\
\hline 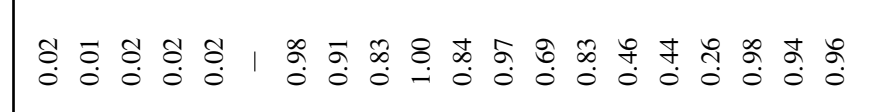 & 点怼 & 恖 & 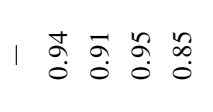 \\
\hline 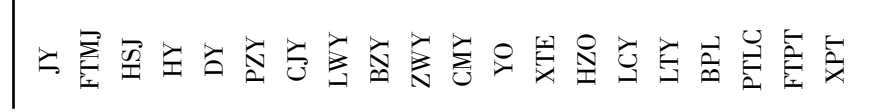 & 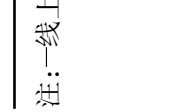 & $\mid \frac{2}{2}$ & 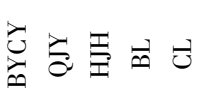 \\
\hline
\end{tabular}




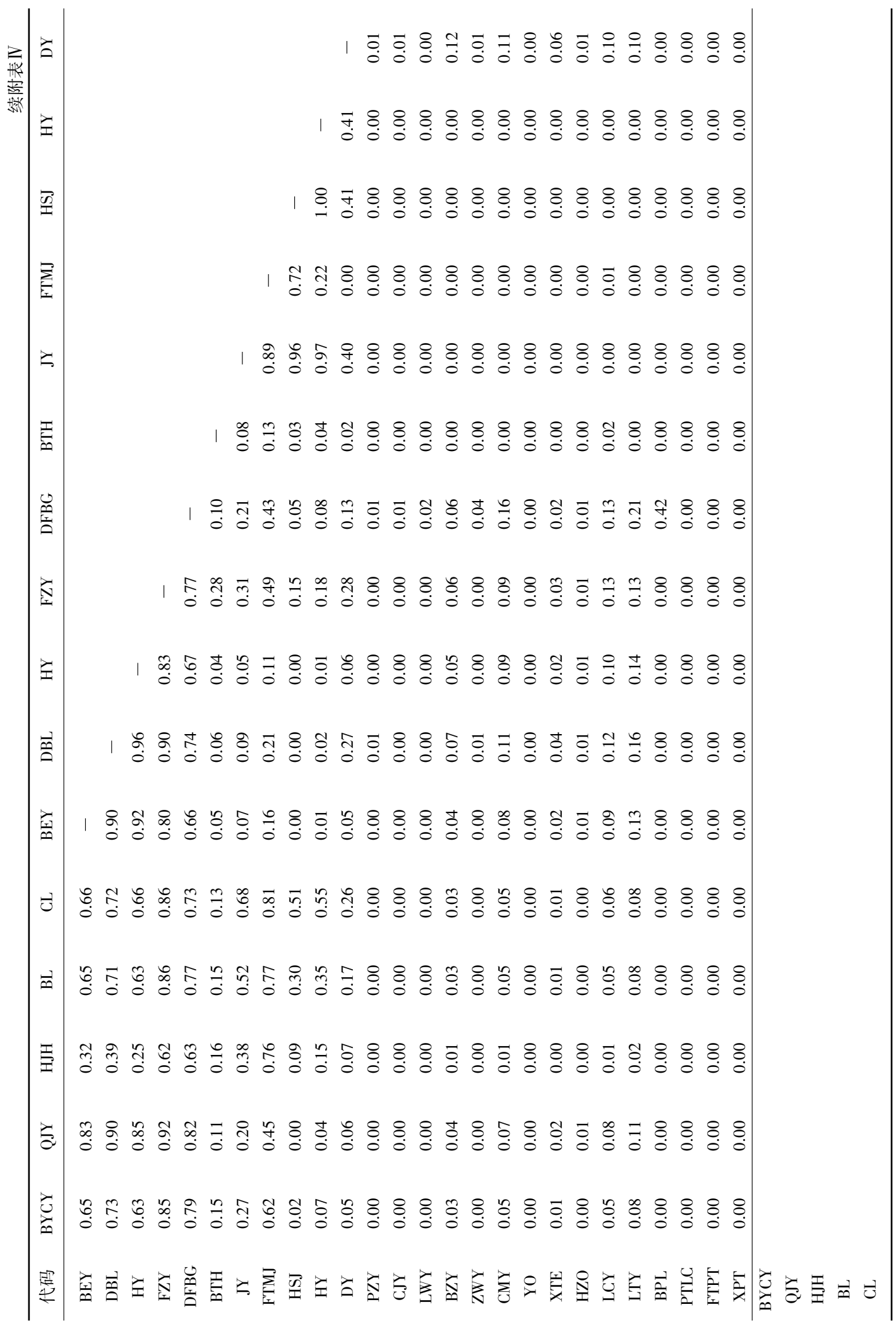




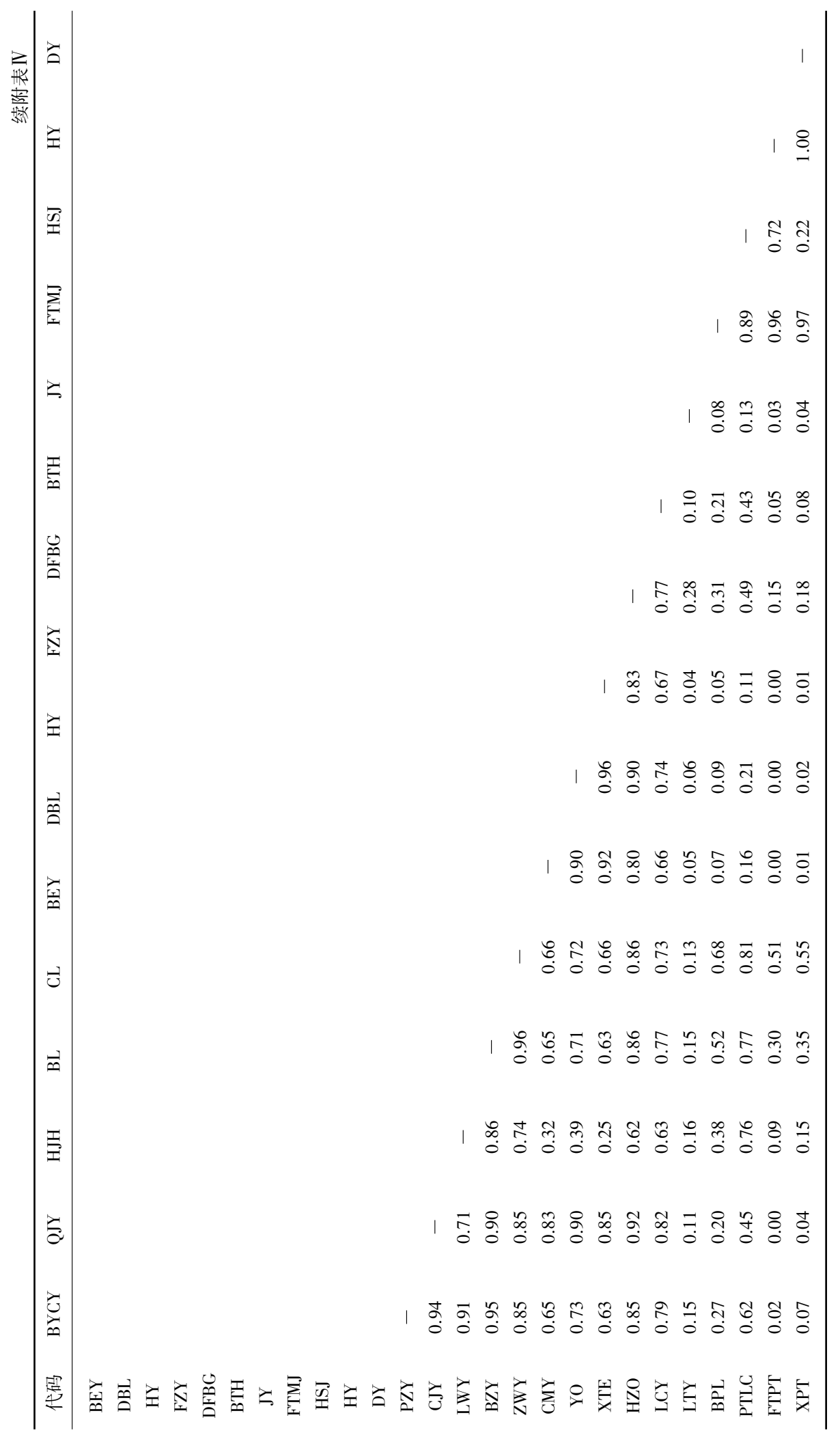

